\title{
Intraoperative intravitreal triamcinolone acetonide injection for prevention of postoperative inflammation and complications after phacoemulsification in patients with uveitic cataract
}

\author{
Yan Ren ${ }^{1,2+}$, Shufang Du ${ }^{1,2+}$, Dongping Zheng ${ }^{2}$, Yanyun Shi², Luping Pan ${ }^{2}$ and Hua Yan ${ }^{1 *}$
}

\begin{abstract}
Background: We aimed to evaluate the efficacy and safety of phacoemulsification with intravitreal $3 \mathrm{mg}$ triamcinolone acetonide injection in preventing postoperative inflammation and complications in patients with non-infectious anterior uveitis and panuveitis complicated cataract.

Method: In this retrospective cohort study, 140 uveitic cataract patients who received phacoemulsification and intraocular lens implantation in Shanxi Eye hospital from January 2018 to January 2020 were reviewed. The IVTA group (51 eyes of 41 patients) received intravitreal injection of $3 \mathrm{mg}$ triamcinolone acetonide (TA) at the end of surgery, and the control group (51 eyes of 41 patients) without injection matched by propensity score matching were enrolled. Outcome measures were best corrected visual acuity (BCVA), anterior chamber inflammation, intraocular pressure, corneal endothelial cell density, central macular thickness and complications within 3 months follow-up.

Results: The degree of postoperative anterior chamber inflammation in the IVTA group was lighter than that in the control group $(P<0.05)$. The postoperative logMAR BCVA of anterior uveitis was better and improved more quickly in the IVTA group $(P<0.05)$. Postoperative time of using corticosteroids was shorter in the IVTA group as compared to the control group $(P<0.05)$. The central macular thickness at postoperative month 1 was statistically significantly lower in the IVTA group $(P<0.05)$. There were no statistically significant differences between the two groups in postoperative corneal endothelial cell density and intraocular pressure $(P>0.05)$. Two of 51 eyes (3.9\%) in the IVTA group and 8 of 51 eyes (15.7\%) in the control group had recurrence of uveitis; 6 of 45 eyes (13.3\%) in the control group developed cystoid macular edema but none in the IVTA group; 11 of 51 eyes (21.6\%) in the IVTA group and 22 of 51 eyes (43.1\%) in the control group developed posterior synechiae postoperatively.

Conclusions: Intraoperative Intravitreal injection of $3 \mathrm{mg}$ TA is an effective and safe adjunctive therapy for preventing postoperative inflammation and complications to promote early recovery for anterior uveitis or panuveitis complicated cataract patients following phacoemulsification.
\end{abstract}

\footnotetext{
* Correspondence: zyyyanhua@tmu.edu.cn

${ }^{\dagger}$ Yan Ren and Shufang Du contributed equally to this work.

'Department of Ophthalmology, Tianjin Medical University General Hospital,

No. 154, Anshan Road, Tianjin 300052, China

Full list of author information is available at the end of the article
}

(c) The Author(s). 2021 Open Access This article is licensed under a Creative Commons Attribution 4.0 International License, which permits use, sharing, adaptation, distribution and reproduction in any medium or format, as long as you give appropriate credit to the original author(s) and the source, provide a link to the Creative Commons licence, and indicate if changes were made. The images or other third party material in this article are included in the article's Creative Commons licence, unless indicated otherwise in a credit line to the material. If material is not included in the article's Creative Commons licence and your intended use is not permitted by statutory regulation or exceeds the permitted use, you will need to obtain permission directly from the copyright holder. To view a copy of this licence, visit http://creativecommons.org/licenses/by/4.0/. The Creative Commons Public Domain Dedication waiver (http://creativecommons.org/publicdomain/zero/1.0/) applies to the data made available in this article, unless otherwise stated in a credit line to the data. 
Trial registration: This retrospective cohort study was in accordance with the tenets of the Helsinki Declaration and was approved by the Shanxi Eye Hospital Ethics Committee. Written informed consent was obtained from all participants for their clinical records to be used in this study.

Keywords: Triamcinolone acetonide, Intravitreal injection, Inflammation, Uveitic cataract, Phacoemulsification

\section{Background}

Uveitis is a leading cause of blindness worldwide, and the development of cataracts is a high-incidence complication due to the intraocular inflammation and/or consequence of long-term treatment with topical, regional and systemic corticosteroids [1-3]. Phacoemulsification with implantation of intraocular lens may be effective in visual rehabilitation but performing cataract surgery in eyes with uveitis has historically been a challenge, being technically more difficult and providing less reliable outcomes than senile cataract. The visual outcome of cataract surgery can be unpredictable due to a greater incidence of recurrent inflammation and postoperative complications, such as macular edema, posterior capsule opacification (PCO) and glaucoma $[4,5]$.

Preoperative and postoperative use of topical and/or systemic corticosteroids is general treatment when patients with non-infectious uveitis receive cataract surgery to restrain the postoperative inflammation. Systemic corticosteroids are effective in the treatment of posterior uveitis, bilateral uveitis and chronic uveitis associated with an underlying systemic disease. However, systemic corticosteroids therapy may accompany significant side effects including gastrointestinal ulcers, osteoporosis, hyperglycaemia, Cushing syndrome, infections and electrolyte disturbance [6].

Intravitreal administration of TA offers the maximal drug efficacy and the lowest risk of systemic side effects. Successful application of intravitreal TA injection has been confirmed in treating patients with inflammation and macular edema associated with posterior uveitis $[7,8]$. Results of some case reports also showed optimistic outcomes after intravitreal TA injection combined with cataract extraction in anterior uveitis patients $[5,9]$. But the the risk of high intraocular pressure was still inevitable and dose-dependent, and potential toxicity such as to the corneal endothelium is also concerned after phacoemulsification. Whether low dose TA could be effective and reduce the risk of side effects has not been reported in patients with panuveitis and anterior uveitis undergoing phacoemulsification.

To our knowledge, there are limited data available in the literature about the preventive effectiveness and adverse effects of $3 \mathrm{mg}$ TA intravitreal injection for the treatment of uveitic cataracts. In this retrospective study, we have compared the postoperative outcomes of phacoemulsification with and without intravitreal injection of $3 \mathrm{mg}$ TA in treatment of cataract patients suffering from chronic anterior uveitis or panuveitis in the real world. This is the first of its kind, retrospective cohort study in which propensity score matching (PSM) have been used to adjust potential confounding factors and screened suitable cases to establish the efficacy and safety of intravitreal TA injection combined with phacoemulsification in preventing the postoperative inflammation and complications in uveitits cases.

\section{Patients and methods}

This retrospective cohort study was in accordance with the tenets of the Helsinki Declaration and was approved by the Shanxi Eye Hospital Ethics Committee. Written informed consent was obtained from all participants for their clinical records to be used in this study, including demographic characteristics, clinical manifestations and treatment procedures.

Patients with non-infectious uveitis complicated cataract who were subjected to phacoemulsification and primary posterior capsule implantation of intraocular lens (IOL) in Shanxi Eye Hospital from January 2018 to January 2020 were enrolled in this study. The IVTA group received intravitreal injection of triamcinolone acetonide $(3 \mathrm{mg} / 0.075 \mathrm{~mL})$ intraoperatively, and the control group didn't.

Inclusion criteria were: (i) the diagnosis of uveitis was consistent with the Standardization Uveitis Nomenclature (SUN), and uveitis was classified as anterior, intermediate, posterior uveitis and panuveitis [10]; (ii) intraocular inflammation had been controlled and without using topical or oral corticosteroids for at least 3 months before surgery; (iii) the LogMAR BCVA of preoperation was not better than 0.5; (iv) patients were followed up for at least 3 months.

Exclusion criteria were: (i) infectious uveitis; (ii) previous intraocular surgery; (iii) patients with history of glaucoma or high myopia, optic neuropathy, media opacity other than cataract; (iv)patients with diabetes mellitus; (v) intraoperative complications like posterior capsular rupture, vitreous loss, etc.; (vi) patients younger than 18 years old or with juvenile rheumatoid arthritis; (vii) retinal or choroidal disease that could affect retinal thickness; (viii) current presence of cystoid macular edema (CME). 


\section{Propensity score matching (PSM)}

PSM analysis is a superior and more refined statistical method of adjusting for potential baseline confounding variables. To reduce bias from confounding factors between groups, a propensity score-matched analysis was done using a multivariable logistic regression model with a tolerance of 0.05 . Matching covariates consisted of age, gender, type of uveitis, duration of active inflammation, unilateral or bilateral uveitis and quiescent time of ocular inflammation.

\section{Preoperative and postoperative examinations}

An internist evaluated each patient to eliminate any significant systemic illness and confirm that the patient's systemic disorder was in a stable period. Preoperative and postoperative examinations included BCVA (decimal visual acuity chart), intraocular pressure (IOP) measurement with the Nidek noncontact tonometer NT-4000 (Nidek Corporation., Aichi, Japan), anterior and posterior segment examinations using slit lamp biomicroscopy, central macular thickness (CMT) measured by Stratus OCT 3000 (Carl Zeiss Meditec, Inc., Dublin, CA), and corneal endothelial cell density generated by the specular microscope SP-3000P (Topcon Corporation, Tokyo, Japan). Bscan ultrasonography was performed to exclude any posterior segment pathology detectable before surgery.

Anterior chamber inflammation was measured in terms of grades of anterior chamber cells and grades of aqueous flare measured on slit lamp examination, with a $1.0 \mathrm{~mm}$ high and $1.0 \mathrm{~mm}$ wide slit beam at a 45 to 60 degree angle (Table 1) [10].

\section{Surgical management and postoperative care}

Written informed consent was taken from every patient before the surgery. All surgeries were performed by same experienced consultant surgeon using topical anaesthesia. Side port incision was created using $15^{\circ}$ disposable knife and primary main port was made with a $3.0 \mathrm{~mm}$ disposable keratome. Posterior synechiae and small pupils were managed by synechiolysis. In cases of dense cataract, trypan blue dye (0.06\%) was used to stain anterior capsule. A $5-5.5 \mathrm{~mm}$ continuous circular

Table 1 Grades of anterior chamber cells and aqueous flare

\begin{tabular}{lllll}
\hline \multicolumn{2}{l}{ Grades of anterior chamber cells } & & \multicolumn{2}{l}{ Grades of aqueous flare } \\
\cline { 1 - 2 } Grade & Cells in field & & Grade & Description \\
\hline 0 & $<1$ & 0 & none \\
+0.5 & $1-5$ & +1 & faint \\
+1 & $6-15$ & +2 & moderate (iris detail clear) \\
+2 & $16-25$ & +3 & marked (iris detail hazy) \\
+3 & $26-50$ & +4 & intense (fibrous exudates) \\
+4 & $>50$ & & \\
\hline
\end{tabular}

capsulorrhexis was created after which hydrodissection, phacoemulsification and foldable hydrophobic acrylic IOL implantation in the capsular bag were performed. The patients in the IVTA group received intravitreal 3.0 $\mathrm{mg}(0.075 \mathrm{ml}) \mathrm{TA}$ injection through the pars plana 3.5 $\mathrm{mm}$ away from the limbus inferotemporally. After surgery they were advised to remain in a semi reclining position for $24 \mathrm{~h}$.

Postoperatively, patients were detained for observation for a couple of days and appointed routinely at postoperative 1 week, 2 weeks, 1 month, 2 months and 3 months, or come to visit at any time if necessary. Additional corticosteroid (oral or invasive) was administered to control the severe postoperative inflammation in time, and patients will receive prompt and appropriate treatment in case of CME, PCO and other complications. All patients were prescribed topical levofloxacin eye drops 6 times a day for a month, prednisolone acetate $1 \%$ eye drops every $2 \mathrm{~h}$ daily for 1 week and compound tropicamide eye drops twice a day for 1 week. After 1 week, the frequency of the prednisolone acetate was subsequently tapered over 6 weeks with reduction of the postoperative inflammation.

\section{Statistical analysis}

The data of this study was analysed using SPSS software version 24.0 and Graphpad Prism Software version 8.0. Descriptive statistics presented as mean (standard deviation). The BCVA readings were converted to logMAR values for statistical analysis. Continuous parameters were analysed with Student's t-test, rank sum test was used for ranked data, and categorical parameters were analysed using chi-square test or Fisher's exact test. The log-rank test compared the use time of corticosteroids between two groups. Differences were considered significant at a $p$ value of $<0.05$.

\section{Results}

Patient characteristics

Overall, a total of 140 patients were reviewed with complete clinical data, including 41 patients who underwent cataract surgery combined with IVTA injection and 99 patients who received cataract surgery alone. Two types of uveitic cataract found received intraoperative TA injection in our study, including anterior uveitis and panuveitis. The age and quiescent time of ocular inflammation between the two groups were not balanced $(t=1.991$, 2.412; $p=0.048,0.017$ ). After PSM, 51 eyes of 41 patients were included in the IVTA group and 51 eyes of $41 \mathrm{pa}$ tients were included in the control group. Pre-existing differences between groups were well balanced, and the preoperative characteristics of the patients were showed in Table 2. Table 3 showes etiological classification of uveitis in patients of two groups. 
Table 2 Baseline characteristics before and after propensity score matching

\begin{tabular}{|c|c|c|c|c|c|c|}
\hline \multirow[t]{2}{*}{ Characteristics } & \multicolumn{3}{|c|}{ Before matching $(n=140)$} & \multicolumn{3}{|c|}{ After matching $(n=82)$} \\
\hline & $\begin{array}{l}\text { IVTA group } \\
(n=41)\end{array}$ & $\begin{array}{l}\text { Control group } \\
(n=99)\end{array}$ & $P$ value & $\begin{array}{l}\text { IVTA group } \\
(n=41)\end{array}$ & $\begin{array}{l}\text { Control group } \\
(n=41)\end{array}$ & $P$ value \\
\hline Age, mean(SD), y & $42.17(7.72)$ & $45.90(10.90)$ & 0.048 & $42.17(7.72)$ & $42.07(8.27)$ & 0.956 \\
\hline Gender, n(\%) & & & 0.888 & & & 1.00 \\
\hline Male & $21(51.22)$ & $52(52.53)$ & & $21(51.22)$ & $21(51.22)$ & \\
\hline Female & $20(48.78)$ & $47(47.47)$ & & $20(48.78)$ & $20(48.78)$ & \\
\hline Location of uveitis, n(\%) & & & 0.599 & & & 0.647 \\
\hline Anterior & $25(60.98)$ & $65(65.66)$ & & $25(60.98)$ & $27(65.85)$ & \\
\hline Panuveitis & $16(39.02)$ & $34(34.34)$ & & $16(39.02)$ & $14(34.15)$ & \\
\hline Duration of active inflammation, mean(SD), m & $7.74(2.72)$ & $6.77(4.09)$ & 0.162 & $7.74(2.72)$ & $6.99(3.12)$ & 0.246 \\
\hline $\begin{array}{l}\text { Quiescent time of } \\
\text { ocular inflammation, mean(SD), m }\end{array}$ & $7.78(2.28)$ & $9.35(3.89)$ & 0.017 & $7.78(2.28)$ & $7.39(2.36)$ & 0.449 \\
\hline Cataract surgery, n(\%) & & & 0.915 & & & 1.00 \\
\hline Unilateral & $31(75.60)$ & $74(74.75)$ & & $31(75.61)$ & $31(75.60)$ & \\
\hline Bilateral & $10(24.40)$ & $25(25.25)$ & & $10(24.39)$ & $10(24.40)$ & \\
\hline
\end{tabular}

\section{Visual acuity}

Table 4 compares the BCVA in the two groups of patients at every follow-up visit. In anterior uveitis patients, the BCVA after operation in IVTA group was statistically significantly better than that in control group $(P<0.05)$. Figure 1 shows that postoperative BCVA recovered faster, and tended to be better in the IVTA group in anterior uveitis. The mean logMAR BCVA of panuveitis was better in IVTA group at postoperative follow-up visit, but there was no statistically significant difference. The main cause of no improvement in vision was pre-existing macular pathology, and recurrence of uveitis and CME were primary reasons of vision regression in late visits.

\section{Intraocular pressure (IOP)}

Table 5 shows the mean IOP of two groups over time; there were no statistically significant differences at baseline and any postoperative visit $(P>0.05)$. There was increased IOP over $21 \mathrm{mmHg}$ in 7 eyes, 4 out of 51 eyes (7.8\%) in the IVTA group and 3 out of 51 eyes (5.9\%) in the control group. One eye with ocular hypertension in the IVTA group was due to TA migrating into the anterior chamber. The transient IOP rise was managed medically with two topical anti-glaucoma eye drops for one week at most.

\section{Anterior chamber inflammation and posterior inflammation}

We analysed grade of the most severe anterior chamber inflammation during postoperative 1 week hospitalisation (Table 6). The control of anterior chamber cells after operation in the IVTA group was better than that in the control group $(P<0.05)$. There was no statistically significant difference in aqueous flare between the two groups. Ten patients received bilateral sequential phacoemulsification in each group, and we found anterior chamber inflammation in the second eye was heavier or the same as in the first eye.

During the 3-month follow-up period, anterior uveitis recurred in 2 eyes in the IVTA group in the 5th week and 5 eyes in the control group in the 1 to 2 months. The recurrence was effectively managed with additional subconjunctival dexamethasone injections and topical

Table 3 Etiological classification of uveitis in patients of two groups

\begin{tabular}{lllll}
\hline $\begin{array}{l}\text { Etiology } \\
\mathbf{n}(\%)\end{array}$ & IVTA group & \multicolumn{2}{c}{ Control group } \\
\cline { 2 - 5 } & $\begin{array}{l}\text { Anterior uveitis } \\
(\boldsymbol{n}=\mathbf{2 5})\end{array}$ & $\begin{array}{l}\text { Panuveitis } \\
(\boldsymbol{n}=\mathbf{1 6})\end{array}$ & $\begin{array}{l}\text { Anterior uveitis } \\
(\boldsymbol{n}=\mathbf{2 7})\end{array}$ & $\begin{array}{l}\text { Panuveitis } \\
(\boldsymbol{n}=\mathbf{1 4})\end{array}$ \\
\hline Idiopathic & $16(64.00)$ & $10(62.50)$ & $8(29.63)$ & $8(57.14)$ \\
HLA-B27-associated uveitis & $9(36.00)$ & - & - & $3(21.43)$ \\
VKH & - & $2(12.50)$ & - & $1(7.14)$ \\
Behcet's disease & - & $2(12.50)$ & - & $2(14.29)$ \\
Endogenous endophthalmitis & - & $1(6.25)$ & $1(3.70)$ & - \\
\hline Sarcoidosis & - & $1(6.25)$ & \\
\hline
\end{tabular}


Table 4 Between-group comparison of LogMAR BCVA over time

\begin{tabular}{|c|c|c|c|c|c|c|c|c|}
\hline & \multicolumn{2}{|c|}{ Anterior uveitis, mean(SD) } & \multirow[t]{2}{*}{$t$ value } & \multirow[t]{2}{*}{$P$ value } & \multicolumn{2}{|c|}{ Panuveitis, mean(SD) } & \multirow[t]{2}{*}{$t$ value } & \multirow[t]{2}{*}{$P$ value } \\
\hline & $\begin{array}{l}\text { IVTA group } \\
(n=28)\end{array}$ & $\begin{array}{l}\text { Control group } \\
(n=34)\end{array}$ & & & $\begin{array}{l}\text { IVTA group } \\
(n=23)\end{array}$ & $\begin{array}{l}\text { Control group } \\
(n=17)\end{array}$ & & \\
\hline Day 0 & $0.97(0.39)$ & $1.01(0.42)$ & 0.376 & 0.709 & $1.22(0.57)$ & $1.28(0.59)$ & 0.288 & 0.775 \\
\hline Day 1 & $0.49(0.22)$ & $0.59(0.21)$ & 2.009 & 0.049 & $0.95(0.58)$ & $1.07(0.56)$ & 0.665 & 0.510 \\
\hline Day 7 & $0.26(0.16)$ & $0.35(0.18)$ & 2.059 & 0.044 & $0.87(0.47)$ & $0.96(0.55)$ & 0.567 & 0.574 \\
\hline Day 30 & $0.13(0.13)$ & $0.20(0.12)$ & 2.123 & 0.038 & $0.79(0.47)$ & $0.85(0.51)$ & 0.357 & 0.723 \\
\hline Day 60 & $0.14(0.15)$ & $0.22(0.16)$ & 2.015 & 0.048 & $0.79(0.46)$ & $0.89(0.52)$ & 0.664 & 0.511 \\
\hline Day 90 & $0.15(0.15)$ & $0.24(0.15)$ & 2.351 & 0.022 & $0.81(0.45)$ & $0.90(0.53)$ & 0.580 & 0.565 \\
\hline
\end{tabular}

corticosteroids. Panuveitis recurred in 3 eyes in the control group from 3 to 4 weeks postoperatively which was diagnosed based on clinical examination and fluorescein angiography, but none in the IVTA group. All 3 patients were given intravitreal injections of $20 \mathrm{mg} \mathrm{TA}$, and two of them received additional oral corticosteroids. The inflammation was controlled and visual acuity was improved at the final follow-up. Of the 10 recurrent eyes, 6 eyes were the second eye of patients who underwent bilateral sequential cataract surgery, and the surgery interval was less than a month.

\section{Corneal endothelial cell density}

Table 7 shows the corneal endothelial cell density at 1 month postoperative visit compared with the preoperative level in two groups. The postoperative density was statistically significantly lower than that preoperative in each group, while there was no significant difference between the two groups postoperatively $(p>0.05)$.

\section{Central macular thickness(CMT)}

The values of mean CMT from preoperatively to postoperatively are shown in Table 8 . The OCT results of 5 eyes in the IVTA group and 6 eyes in the control group were not available because of thick opacity of cataract, so they were not included in the statistics. At postoperative 1 month, CMT was statistically lower in the IVTA group as compared to the control group. At 3 months, CMT was lower in the IVTA group than the control group, but it was not statistically significant. This might be attributed to the remission of macular edema in patients who received appropriate treatment.

\section{Duration of continuous use of corticosteroids}

Log-rank (Mantel-Cox) analysis revealed that postoperative time of using topical or oral corticosteroids in the IVTA group is statistically reduced compared to the control group $(P<0.05)$. Figure 2 shows that in the IVTA group, the inflammation of all patients was controlled within 11 weeks, while in the control group, it took longer to taper corticosteroids to control the persistent intraocular inflammation or complications. Long-term of typical and systemic corticosteroids, or in combination with IVTA injection, were used for patients with persistent inflammation or CME in the control group.

\section{Complications}

In the control group, a total of 7 eyes developed CME, out of which 6 eyes $(13.3 \%)$ were without preoperative CME and one eye was failed to obtain the macular structure as a result of mature cataract. Most patients developed CME at around 1 month, which were treated with either oral corticosteroids or posterior sub-Tenon's

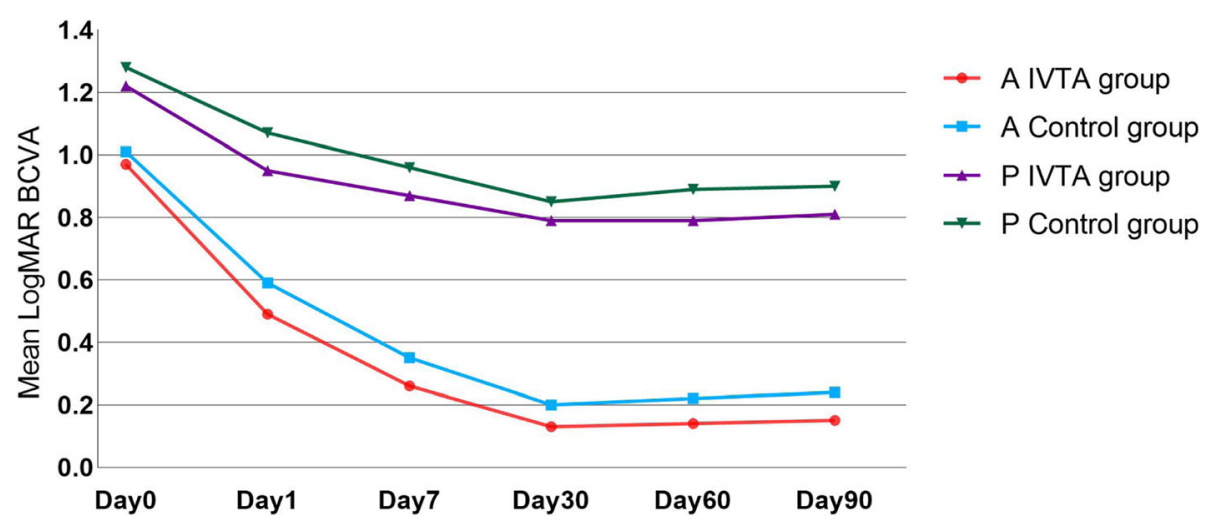

Fig. 1 Graph showing trend of mean LogMar BCVA from preoperative to postoperative follow-up visits. (A-anterior uveitis; P-panuveitis) 
Table 5 Between-group comparison of IOP over time $(n=51)$

\begin{tabular}{lllll}
\hline & \multicolumn{2}{l}{ Mean IOP(SD), $\mathbf{m m H g}$} & \multirow{t}{*}{ value } & $\boldsymbol{P}$ value \\
\cline { 2 - 3 } & IVTA group & Control group & & \\
\hline Day 0 & $15.49(3.26)$ & $15.12(3.40)$ & 0.565 & 0.574 \\
Day 1 & $15.68(3.31)$ & $16.14(4.20)$ & 0.603 & 0.548 \\
Day 7 & $15.84(2.96)$ & $15.82(2.49)$ & 0.029 & 0.977 \\
Day 14 & $15.86(2.49)$ & $15.39(2.88)$ & 0.882 & 0.380 \\
Day 30 & $15.92(2.63)$ & $15.29(2.85)$ & 1.155 & 0.251 \\
Day 60 & $15.90(2.68)$ & $15.33(2.78)$ & 1.050 & 0.296 \\
Day 90 & $15.75(2.62)$ & $15.69(3.04)$ & 0.105 & 0.917 \\
\hline
\end{tabular}

injection of $20 \mathrm{mg}$ TA, depending upon severity. No patient in the IVTA group developed CME during follow-up visits.

Iris synechia mainly occurred in patients with severe postoperative anterior chamber inflammation or patients already with posterior synechiae before surgery. A total of 33 eyes developed posterior synechiae postoperatively, including 22 of 51 eyes (43.1\%) in the control group and 11 of 51 eyes $(21.6 \%)$ in the IVTA group.

Posterior capsular opacification requiring Nd:YAG capsulotomy developed in 8 of 51 eyes (15.7\%) in the IVTA group and in 13 of 51 eyes (25.5\%) in the control group.

Hyphaemia occurred in 4 of 51 eyes $(7.8 \%)$ in the IVTA group and 6 of 51 eyes (11.8\%) in the control group on postoperative day 1 , which were resolved spontaneously in about 4 days and 7 days respectively.

\section{Discussion}

Although there is some literature reporting the efficacy of IVTA in the treatment of uveitic cataract [5, 11], there have been no previous controlled trial comparisons. We conducted a retrospective cohort study to evaluate visual outcomes and postoperative complications after phacoemulsification combined with IVTA injection for uveitic cataract in the real world.

The lower age limit of 18 years was adopted to exclude juvenile rheumatoid arthritis, because IOL implantation in these cases may lead to more severe postoperative inflammation than other patients, in addition comprehensive treatment was applied into the postoperative management. We reviewed characteristics of 99 patients of uveitis complicated with cataract who underwent cataract surgery alone, and the mean age of which was older, and quiescent time of ocular inflammation was longer than that of IVTA group. PSM has been increasingly used as a statistical tool in observational studies. Clinical and demographic patient characteristics can be balanced between groups [12]. Potential confounding factors of this study, including age, gender, type of uveitis, duration of active inflammation, unilateral or bilateral sequential surgery and quiescent time of ocular inflammation were well-adjusted to mimic randomised controlled trial design. Patients in the IVTA group was well-matched after PSM, and the potential component of senile cataract was reduced.

In order to compare the visual outcome between two groups without regard to fundus disease, BCVA was analysed in anterior uveitis patients and panuveitis patients respectively. The BCVA improved significantly after phacoemulsification in the anterior uveitis patients, with $89.3 \%$ of patients in the IVTA group achieving 0.3 LogMAR or better visual acuity at 3 months. These results are comparable to those in previous studies showing visual acuity outcome better than 0.3 LogMAR in $67-82 \%$ cases $[1,11,13-15]$. In panuveitis patients, postoperative BCVA mildly improved in two groups, and sequelae of chronic posterior inflammation was found to be the most important factor for determining the improvement of visual acuity. The trend of postoperative BCVA improvement indicated that the application of TA resulted in early recovery in patients, which can also be appreciated on Kaplan-Meier curve. As tapering and withdrawal of corticosteroids were individually prescribed according to following examinations, short time of corticosteroids administration indicated rapid recovery. The intravitreal injection of TA inhibited the potential complications and rebound of inflammation during the postoperative visits, so patients in the IVTA group recovered quickly in the IVTA group as compared to the control group.

Preoperative control of uveitis for at least 3 months is a prerequisite to performing cataract surgery in patients

Table 6 Comparison of anterior chamber cells and aqueous flare during hospitalization $(n=51)$

\begin{tabular}{|c|c|c|c|c|c|c|c|c|c|c|c|c|}
\hline & \multicolumn{6}{|c|}{ Grade of anterior chamber cells } & \multicolumn{6}{|c|}{ Grade of aqueous flare } \\
\hline & \multirow{2}{*}{$\begin{array}{l}\text { Preoperative } \\
0\end{array}$} & \multicolumn{5}{|c|}{ Postoperative } & \multirow{2}{*}{$\begin{array}{l}\text { Preoperative } \\
\leq+1\end{array}$} & \multicolumn{5}{|c|}{ Postoperative } \\
\hline & & 0 or +0.5 & +1 & +2 & +3 & +4 & & 0 & +1 & +2 & +3 & +4 \\
\hline IVTA group & 51 & 2 & 27 & 18 & 4 & 0 & 51 & 0 & 1 & 41 & 9 & 0 \\
\hline Control group & 51 & 1 & 20 & 19 & 8 & 3 & 51 & 0 & 1 & 33 & 13 & 4 \\
\hline$Z$ value & & 2.119 & & & & & & 1.8 & & & & \\
\hline$P$ value & & $0.034^{*}$ & & & & & & & & & & \\
\hline
\end{tabular}

\footnotetext{
"Fisher's exact test
} 
Table 7 Comparison of corneal endothelial cell density $(n=51)$

\begin{tabular}{|c|c|c|c|c|}
\hline & Corneal endoth & D), cell $/ \mathrm{mm}^{2}$ & $t$ value & $P$ value \\
\hline & Day 0 & Day 30 & & \\
\hline IVTA group & $2440.88(303.54)$ & $2146.00(288.60)$ & 5.028 & 1.00 \\
\hline Control group & $2502.86(281.58)$ & 2173.55 (278.15) & 5.942 & 1.00 \\
\hline$t$ value & 1.069 & 0.491 & & \\
\hline$P$ value & 0.288 & 0.625 & & \\
\hline
\end{tabular}

with uveitis [16]. Prompt and appropriate treatment is also necessary to reverse visual deterioration in case of postoperative inflammation. According to the data, some patients had an outbreak in anterior chamber inflammation in the immediate postoperative period, especially more severe inflammation in the control group, which was progressively controlled by timely multiple subconjunctival dexamethasone injection. All 3 eyes of recurrent panuveitis and 7 eyes developed CME occurred in the control group, which inflammation and visual acuity was improved at the final follow-up, due to intravitreal or posterior sub-Tenon's injection of TA and oral corticosteroids. Patients with panuveitis in the control group received comparable visual acuity to the IVTA group within postoperative 3 months. Regrettably, remedies brought additional pain and risk of adverse effects to patient, and postoperative inflammation lead to more patients suffering from iris posterior synechia and $\mathrm{PCO}$ in the control group. In addition, we found that intraoperative injection of TA seemed more necessary for these patients with refractory uveitis, including bilateral uveitis and panuveitis, which tend to severe postoperative reactions and recurrence with a high probability of oral corticosteroids application.

In our study, ocular hypertension occurred in 3 eyes (7.8\%) in the IVTA group range from 22 to $30 \mathrm{mmHg}$, including one case caused by anterior chamber migration of triamcinolone crystals. The maximum of increased IOP eyes recorded in the control group was $40 \mathrm{mmHg}$, and of all 4 eyes with ocular hypertension occurred during postoperative 1 week, which could be attributed to the severe anterior chamber inflammation. There wasn't an increased incidence of ocular hypertension, as it was supposed to be about 20.9-43.3\% caused by TA injection alone reported by previous studies without cataract surgery [17-19]. Tanuj et al. showed intravitreal injection of $4 \mathrm{mg}$ TA had anti-inflammatory efficacy clinically equivalent to oral corticosteroids postoperatively in uveitis patients with cataract surgery [11]. However, ocular hypertension was seen in up to $25 \%$ of patients in the IVTA group. One of the possible reasons is that a dose of $3 \mathrm{mg}$ injection of TA in our study reduced the incidence of elevated IOP. Another is that 3 months quiescent period without corticosteroids use reduced the possibility of steroid-induced ocular hypertension.

Three regional TA injections have been reported to be efficient to control ocular inflammation: periocular TA, intravitreal TA and intracameral TA. Jennifer E Thorne et.al suggested that intravitreal TA was superior to periocular TA for treating uveitic macular edema with modest increases in the risk of IOP elevation [20]. Compared with intracameral injection of TA, intravitreal injection can reduce the increase of IOP and damage of corneal endothelial cell caused by high drug concentration of anterior chamber, as we found that IVTA did not aggravate the decrease of corneal endothelial cell density after phacoemulsification. In addition, combined cataract surgery would be advantageous to maintain anterior aqueous humour drug concentration through aqueous humour circulation to control anterior chamber inflammation. What's more, IVTA could inhibit postoperative macular edema and posterior uveitis directly. Thus, IVTA is a promising approach to control anterior and posterior uveitis in cataract surgery.

Previous studies reported that triamcinolone is detectable in anterior chamber and vitreous after a single intravitreal injection for 3 to 8 months, even though triamcinolone crystals were no longer detected in the vitreous cavity on ophthalmoscopic examination [21, 22]. This suggests that

Table 8 Between-group comparison of central macular thickness (CMT)

\begin{tabular}{llll}
\hline & CMT, mean (SD), $\boldsymbol{\mu m}$ & & \\
\cline { 2 - 4 } & preoperative & postoperative & $\mathbf{3}$ months \\
\hline IVTA group $(n=46)$ & & $\mathbf{1}$ month & $228.62(44.30)$ \\
Control group $(n=45)$ & $237.25(48.36)$ & $230.52(45.73)$ & $247.76(52.05)$ \\
$t$ value & $245.15(53.18)$ & $253.67(58.45)$ & 1.890 \\
$P$ value & 0.614 & 2.107 & 0.062 \\
\hline
\end{tabular}




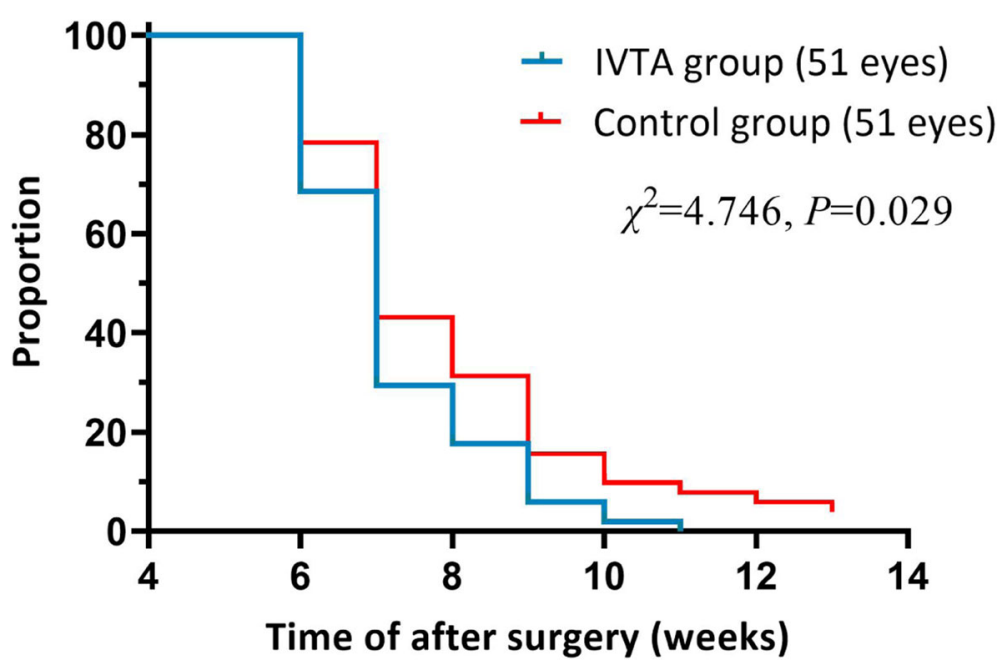

Fig. 2 Kaplan-Meier curve showing proportion of postoperative corticosteroids use over the follow-up period in two groups

one may be able to obtain relatively long-standing concentrations of triamcinolone in the eye with a single injection [21]. Our study proved that $3 \mathrm{mg}$ IVTA was effective to inhibit perioperative inflammation and preserve visual acuity for at least 3 months without IOP elevation in patients received phacoemulsification. Dexamethasone implant has been introduced into clinical treatment of non-infectious uveitis with treatment benefit sustained for 6 months [23]. In a small sample size study by Gaurav et al., intraoperative intravitreal dexamethasone implant was efficacious in controlling the postoperative inflammation and reducing chances of CME without IOP elevation in uveitic cataract for 6 months [24]. But another investigation by Jennifer $E$ Thorne et al. showed that intravitreal dexamethasone did not have a lower risk of IOP elevation than IVTA [20]. Thus, IVTA injection was not challenged its position in prevention of postcataract intraocular inflammation in patients with quiescent uveitis, and economic advantage can also be taken into account, especially in relatively underdeveloped regions. Dang et al. reported that both IVTA and dexamethasone implant could equally restore visual function and recover morphological change effectively in diabetic CME for at least 6 months, but repeated intravitreal injection was required in the IVTA group [25]. For uveitc patients with pre-existing persistent CME who have to perform cataract surgery, repeated TA intravitreal injection might be required after surgery, while dexamethasone implant could be a better choice due to its slightly longlasting effect than TA [26]. A cost-effectiveness study comparing intravitreal dexamethasone implants versus IVTA would be necessary to provide the reference criterion for individual treatment in uveitic patients.

Cystoid macular edema is considered as the most common complication following cataract surgery in cases of uveitic cataract. According to our data, postoperative CME was seen in 6 of 45 eyes (13.3\%,) control eyes, excluded one eye of CME without preoperative OCT result. The reported incidence varies and has been described to occur in the range from $2 \%$ by Suresh et al. to $33 \%$ by Estafanous et al. [4, 27, 28], which is comparable with our results. In the IVTA group, no patient developed CME in the postoperative 3 months, so to forestall inflammation is a key in avoiding severe inflammation after cataract surgery and consequently, the development of CME. Postoperative anti-inflammation afterward is not sufficient to prevent development of CME unless prophylactic oral corticosteroids were used [11].

Iris posterior synechiae is common in nearly all types of uveitic cataracts. It necessitates additional operative procedures during the surgery, which stimulate the iris and increase the risk of postoperative vascular leakage [14]. Postoperatively, the IVTA group seemed associated with a lower frequency of hyphaemia, and it spontaneously resolved faster than the control group. Previous study reported that intraoperative injection of TA at the end of diabetic vitrectomy was a useful adjunctive therapy for reducing early postoperative vitreous haemorrhage [29]. We are inspired that whether intraocular injection of TA play a role in exerting haemostasis, and further big-sample studies are necessary to better define this advantage.

Limitation of our study was that we didn't have enough uveitic cataract patients with $3 \mathrm{mg}$ IVTA injection, and data on other different types of uveitis are not available. Further large-scale and prospective randomized controlled trials comparing with other dose or new corticosteroids are necessary to highlight efficacy of $3 \mathrm{mg}$ IVTA for cataract patients with some certain aetiology uveitis. 


\section{Conclusions}

Our study clearly shows that $3 \mathrm{mg}$ TA intravitreal injection at the end of phacoemulsification can result in low-grade postoperative inflammation and fast vision rehabilitation, less incidence of complications (CME, iris synechia and PCO), and negligible adverse effects for 3 months, sparing the usage time of corticosteroids. So, we conclude that low-dose of $3 \mathrm{mg}$ TA intravitreal injection is an effective, very safe and economic option for preventing postoperative inflammation and complications in the treatment of patients with anterior uveitis and panuveitis undergoing phacoemulsification.

\section{Abbreviations \\ TA: Triamcinolone acetonide; IVTA: Intravitreal triamcinolone acetonide; BCVA: Best corrected visual acuity; PSM: Propensity score matching; IOP: Intraocular pressure; CMT: Central macular thickness; PCO: posterior capsule opacification; CME: Cystoid macular edema; IOL: Intraocular lens}

\section{Acknowledgements}

Not applicable.

\section{Authors' contributions}

HY conceived and designed the study. YR, SFD and LPP collected and reviewed the patient data. DPZ and YYS analyzed the data and provided interpretation. YR was the major contributor in writing the manuscript. All authors read and approved the final manuscript.

\section{Funding}

This is supported by the National Natural Science Foundation of China (grant numbers, 82020108007, 81830026), and Beijing-Tianjin-Hebei Special Project (grant number 19JCZDJC64300(Z))

\section{Availability of data and materials}

The analytical data in this study could be obtained from the corresponding author upon reasonable request.

\section{Declarations}

\section{Ethics approval and consent to participate}

This retrospective cohort study was in accordance with the tenets of the Helsinki Declaration and was approved by the Shanxi Eye Hospital Ethics Committee. Written informed consent was obtained from all participants for their clinical records to be used in this study.

\section{Consent for publication}

Not applicable.

\section{Competing interests}

The authors declare no conflict of interest.

\section{Author details}

${ }^{1}$ Department of Ophthalmology, Tianjin Medical University General Hospital, No. 154, Anshan Road, Tianjin 300052, China. ${ }^{2}$ Department of Fundus

Diseases, Shanxi Eye Hospital, Taiyuan 030002, Shanxi, China.

Received: 29 March 2021 Accepted: 27 May 2021

Published online: 04 June 2021

\section{References}

1. Mehta S, Linton MM, Kempen JH. Outcomes of cataract surgery in patients with uveitis: a systematic review and meta-analysis. Am J Ophthalmol. 2014; 158(4):676-92. https://doi.org/10.1016/j.ajo.2014.06.018.

2. Llop SM, Papaliodis GN. Cataract surgery complications in uveitis patients: a review article. Semin Ophthalmol. 2018;33(1):64-9. https://doi.org/10.1080/ 08820538.2017.1353815.

3. Chu CJ, Dick AD, Johnston RL, Yang YC, Denniston AK. UK Pseudophakic macular edema study group. Cataract surgery in uveitis: a multicentre database study. Br J Ophthalmol. 2017;101(8):1132-7. https://doi.org/10.113 6/bjophthalmol-2016-309047.

4. Suresh PS, Jones NP. Phacoemulsification with intraocular lens implantation in patients with uveitis. Eye (Lond). 2001;15(Pt 5):621-8. https://doi.org/10.1 038/eye.2001.197.

5. Alkawas AA, Hamdy AM, Shahien EA. Intraoperative intravitreal injection of triamcinolone acetonide for cataract extraction in patients with uveitis. Ocul Immunol Inflamm. 2010;18(5):402-7. https://doi.org/10.3109/09273948.201 0.486098

6. Buchman AL. Side effects of corticosteroid therapy. J Clin Gastroenterol. 2001;33(4):289-4. https://doi.org/10.1097/00004836-200110000-00006.

7. Morshid MM, Zaki HA, Alkawas AA. Intravitreal injection of triamcinolone acetonide in non-infectious uveitis. Bull Ophthalmol Soc Egypt. 2003;96(4): $655-8$.

8. Sugita S. Intravitreal anti-inflammatory treatment for uveitis. $\mathrm{Br} \mathrm{J}$ Ophthalmol. 2007;91(2):135-6. https://doi.org/10.1136/bjo.2006.105601.

9. Okhravi N, Morris A, Kok HS, et al. Intraoperative use of intravitreal triamcinolone in uveitic eyes having cataract surgery: pilot study. J Cataract Refract Surg. 2007;33(7):1278-83. https://doi.org/10.1016/j.jcrs.2007.03.030.

10. Jabs DA, Nussenblatt RB, Rosenbaum JT. Standardization of uveitis nomenclature (SUN) working group. Standardization of uveitis nomenclature for reporting clinical data. Results of the first international workshop. Am J Ophthalmol. 2005;140(3):509-16. https://doi.org/10.1016/j.a jo.2005.03.057.

11. Dada T, Dhawan M, Garg S, Nair S, Mandal S. Safety and efficacy of intraoperative intravitreal injection of triamcinolone acetonide injection after phacoemulsification in cases of uveitic cataract. J Cataract Refract Surg. 2007;33(9):1613-8. https://doi.org/10.1016/j.jcrs.2007.04.029.

12. Elze MC, Gregson J, Baber U, et al. Comparison of propensity score methods and covariate adjustment: evaluation in 4 cardiovascular studies. J Am Coll Cardiol. 2017;69(3):345-57. https://doi.org/10.1016/j.ja cc.2016.10.060

13. Mora P, Gonzales S, Ghirardini S, et al. Perioperative prophylaxis to prevent recurrence following cataract surgery in uveitic patients: a two-Centre, prospective, randomized trial. Acta Ophthalmol. 2016;94(6):e390-4. https:// doi.org/10.1111/aos.12955.

14. YJi Y, Hu K, Li C, et al. Outcome and prognostic factors of phacoemulsification cataract surgery in Vogt-Koyanagi-Harada uveitis. Am J Ophthalmol. 2018;196:121-8. https://doi.org/10.1016/j.ajo.2018.08.041.

15. Akova YA, Foster CS. Cataract surgery in patients with sarcoidosis-associated uveitis. Ophthalmology. 1994;101(3):473-9. https://doi.org/10.1016/s01616420(94)31310-8.

16. Conway MD, Stern E, Enfield DB, Peyman GA. Management of cataract in uveitis patients. Curr Opin Ophthalmol. 2018;29(1):69-74. https://doi.org/10.1 097/ICU.0000000000000438.

17. Chan CK, Fan DS, Chan WM, Lai WW, Lee WY, Lam DS. Ocular-hypertensive response and corneal endothelial changes after intravitreal triamcinolone injections in Chinese subjects: a 6-month follow-up study. Eye (Lond). 2005; 19(6):625-30. https://doi.org/10.1038/sj.eye.6701585.

18. Chang YC, Wu WC. Elevation of intraocular pressure after intravitreal injection of triamcinolone acetonide in Taiwanese patients. Kaohsiung J Med Sci. 2008;24(2):72-7. https://doi.org/10.1016/S1607-551X(08)70100-1.

19. Park HY, Yi K, Kim HK. Intraocular pressure elevation after intravitreal triamcinolone acetonide injection. Korean J Ophthalmol. 2005;19(2):122-7. 15988928. https://doi.org/10.3341/kjo.2005.19.2.122.

20. Thorne JE, Sugar EA, Holbrook JT, et al. Periocular triamcinolone vs. Intravitreal triamcinolone vs. Intravitreal dexamethasone implant for the treatment of Uveitic macular edema: the PeriOcular vs. INTravitreal corticosteroids for uveitic macular edema (POINT) trial. Ophthalmology. 2019;126(2):283-95. https://doi.org/10.1016/j.ophtha.2 018.08.021.

21. Kamppeter BA, Cej A, Jonas JB. Intraocular concentration of triamcinolone acetonide after intravitreal injection in the rabbit eye. Ophthalmology. 2008; 115(8):1372-5. https://doi.org/10.1016/j.ophtha.2008.01.019.

22. Beer PM, Bakri SJ, Singh RJ, Liu W, Peters GB 3rd, Miller M. Intraocular concentration and pharmacokinetics of triamcinolone acetonide after a single intravitreal injection. Ophthalmology. 2003;110(4):681-6. https://doi. org/10.1016/S0161-6420(02)01969-3.

23. Whitcup SM, Robinson MR. Development of a dexamethasone intravitreal implant for the treatment of noninfectious posterior segment uveitis. Ann N Y Acad Sci. 2015;1358:1-12. https://doi.org/10.1111/nyas.12824. 
24. Gupta G, Ram J, Gupta V, et al. Efficacy of Intravitreal dexamethasone implant in patients of uveitis undergoing cataract surgery. Ocul Immunol Inflamm. 2019;27(8):1330-8. https://doi.org/10.1080/09273948.2018.1524498.

25. Dang Y, Mu Y, Li L, et al. Comparison of dexamethasone intravitreal implant and intravitreal triamcinolone acetonide for the treatment of pseudophakic cystoid macular edema in diabetic patients. Drug Des Devel Ther. 2014 Sep 18;8:1441-9. https://doi.org/10.2147/DDDT.S66611.

26. Sallam A, Taylor SR, Lightman S. Review and update of intraocular therapy in noninfectious uveitis. Curr Opin Ophthalmol. 2011;22(6):517-2. https://doi. org/10.1097/ICU.0b013e32834bbd68.

27. Estafanous MF, Lowder CY, Meisler DM, Chauhan R. Phacoemulsification cataract extraction and posterior chamber lens implantation in patients with uveitis. Am J Ophthalmol. 2001;131(5):620-5. https://doi.org/10.1016/500029394(00)00909-0.

28. Ganesh SK, Mistry S. Phacoemulsification with intraocular Lens implantation in pediatric uveitis: a retrospective study. Ocul Immunol Inflamm. 2018;26(2): 305-2. https://doi.org/10.1080/09273948.2016.1206944.

29. Park DH, Shin JP, Kim SY. Intravitreal injection of bevacizumab and triamcinolone acetonide at the end of vitrectomy for diabetic vitreous hemorrhage: a comparative study. Graefes Arch Clin Exp Ophthalmol. 2010; 248(5):641-50. https://doi.org/10.1007/s00417-009-1247-7.

\section{Publisher's Note}

Springer Nature remains neutral with regard to jurisdictional claims in published maps and institutional affiliations.

Ready to submit your research? Choose BMC and benefit from:

- fast, convenient online submission

- thorough peer review by experienced researchers in your field

- rapid publication on acceptance

- support for research data, including large and complex data types

- gold Open Access which fosters wider collaboration and increased citations

- maximum visibility for your research: over $100 \mathrm{M}$ website views per year

At $\mathrm{BMC}$, research is always in progress.

Learn more biomedcentral.com/submissions 